\title{
Open Science and Research Data policy mandates and requirements on Principal Investigators (PIs)
}

\section{Simon Hodson, Executive Director, CODATA}

This invited presentation will explore the policy landscape relating to research data. It aims to cast light on the latest developments in funder, institutional and journal policies and to clarify a number of issues relating to Open Science, Open Data, FAIR Data, Research Data Management etc.

A simplified but useful and well-tested typology describes three categories of publicly-funded research data: 1) data resulting from large data creation/collection exercises that are often cumulative (e.g. EO/remote sensing, statistical data, meteorological data, refined crystallographic data); 2) full datasets created by funded research projects; 3 ) data that directly underpins research publications as the evidence (often a subset of 2). The presentation will analyse the data policies that exist in relation to these 'types' of data and the requirements they impose upon Principal Investigators and other parties.

The presentation will examine the benefits and challenges of Open Science and FAIR data in relation to the following issues and developments:

- $\quad$ the major transformations and opportunities described in the Science International Accord on Open Data in a Big Data World;

- $\quad$ the implications for peer-review, for the scrutiny and validation of data, and for the way in which scientific contribution is assessed and recognised;

- $\quad$ the need and opportunities for international development and coordination of standards and vocabularies within and across established disciplines;

- the funding, governance and economic challenges for data resources being addressed by the CODATA - OECD Global Science Forum Project on Business Models for Sustainable Research Data Repositories; 